\title{
SANEAMENTO BÁSICO E SUA RELAÇÃO COM A QUALIDADE DE VIDA NOS ASSENTAMENTOS DO MUNICÍPIO DE TEODORO SAMPAIO - SP
}

André Turin Santana ${ }^{1}$

\section{Caroline Kraus Luvizotto ${ }^{2}$}

\section{Renata Medici Frayne Cuba ${ }^{3}$}

RESUMO: Assentamentos rurais são empreendimentos do Governo Federal onde propriedades rurais latifundiárias são desapropriadas e divididas em lotes concedidos a diversas famílias de trabalhadores rurais, com objetivo de proporcionar às famílias o alcance de maior igualdade social, melhor distribuição do poder político, melhorias de ordem econômica e uma boa qualidade de vida. Para alcançar tais objetivos os assentamentos exigem planejamento e o fornecimento de infraestrutura básica. Mas o que se observa com freqüência nos assentamentos rurais da reforma agrária Brasileira, é que na maioria das vezes, não apresentam condições favoráveis de infraestrutura e principalmente de saneamento básico, impactando diretamente na qualidade de vida da comunidade assentada, visto que, somente a conquista da terra não proporciona qualidade de vida. A cidade de Teodoro Sampaio situada na região do Pontal do Paranapanema - SP é atualmente conhecida como a "capital da Reforma Agrária", frente à relevante importância no cenário da reforma agrária. Este artigo tem como objetivo refletir acerca da relação entre o saneamento básico e a qualidade de vida nos assentamentos rurais da reforma agrária do município de

\footnotetext{
${ }^{1}$ Mestrando em Meio Ambiente e Desenvolvimento Regional, Universidade do Oeste Paulista - UNOESTE. andretquimico@yahoo.com.br

${ }^{2}$ Doutora em Ciências Sociais pela Universidade Estadual Paulista - UNESP. Docente do Mestrado em Meio Ambiente e Desenvolvimento Regional da UNOESTE. carol.luvizotto@unoeste.br

${ }^{3}$ Doutora em Hidráulica e Saneamento pela Escola de Engenharia de São Carlos - USP. Docente do Mestrado em Meio Ambiente e Desenvolvimento Regional da UNOESTE. renatamedici@unoeste.br
} 


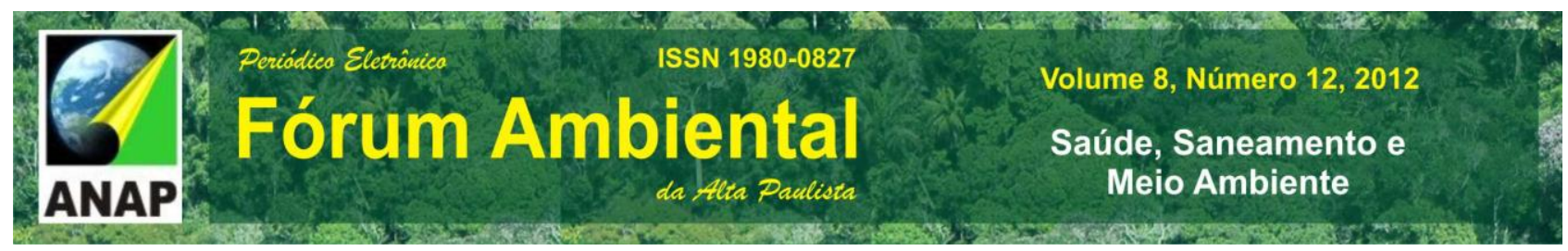

Teodoro Sampaio. Após o estudo, que utilizou a pesquisa bibliográfica e pesquisa documental, compreendeu-se que é inegável a importância dos serviços de saneamento básico para assegurar a qualidade de vida, e como objeto de reflexão, os assentamentos rurais de Teodoro Sampaio mostram o que acontece na maioria dos assentamentos brasileiros com a falta de infraestrutura e saneamento básico.

Palavras-chave: Assentamento rural; Saneamento Básico; Qualidade de vida.

\section{INTRODUÇÃO}

Assentamentos rurais são empreendimentos do Governo Federal, onde propriedades rurais latifundiárias são desapropriadas e divididas em lotes concedidos a diversas famílias de trabalhadores rurais e cada família passa a ter autonomia para utilizar seu lote como convém (FRANZINI, 2010).

Esse tipo de empreendimento veio com o intuito de proporcionar às famílias de pequenos agricultores e trabalhadores agrícolas de baixa renda que foram afastados de suas terras, o alcance de maior igualdade social, melhor distribuição do poder político e melhorias de ordem econômica (SOUZA, KHAN, PASSOS, 2004).

Com relação a esse tema, Mazzini et. al (2007) afirmam que os assentamentos possuem importante papel tanto no campo quanto na cidade dos municípios nos quais são implantados refletindo diretamente na economia regional, além de, devolver ou oferecer pela primeira vez, ao sujeito mais do que um meio de produção, mas juntamente com ele, vem também a moradia, a alimentação, o trabalho e muitas outras oportunidades de escolha para seu futuro e o de seus filhos.

Porém, ainda de acordo com os autores, há necessidade em se construir um novo modelo de desenvolvimento considerando o campo como espaço de inclusão social, a partir de uma nova visão territorial sobre os processos de desenvolvimento.

Nesse sentido, de acordo com Franzini (2010), o assentamento deve ser visto como um empreendimento que exige planejamento de uso e ocupação da área, que vai além da partilha, sendo necessária a delimitação de reservas de proteção, recuperação de matas ciliares, criação de áreas de geração de renda coletiva, assim como, o fornecimento de infraestrutura básica, como por exemplo, estradas, rede de energia elétrica, esgotamento sanitário, fornecimento de água potável entre outros. 


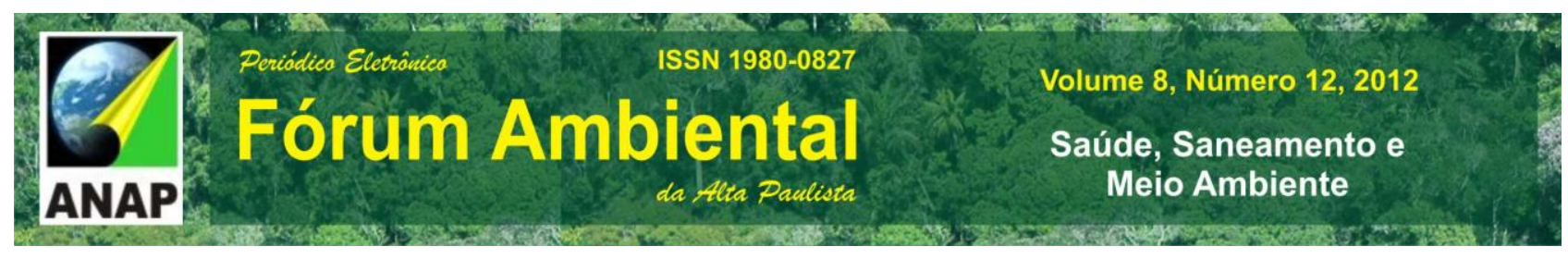

Mesmo recebendo suporte financeiro e técnico, para sua implantação os assentamentos rurais geridos por instituições governamentais como a Fundação Instituto de Terras do Estado de São Paulo - ITESP e o Instituto Nacional de Colonização e Reforma Agrária - INCRA, ainda, na maioria das vezes, não apresentam condições favoráveis de saneamento, principalmente devido à ausência de sistemas seguros de captação e distribuição de água para consumo e de esgotamento sanitário adequado, além da falta de programas de conscientização para boas práticas de higiene e educação sanitária (SANTOS FILHO, 2001).

Segundo a Organização Mundial da Saúde - OMS o saneamento é um controle de todos os fatores do meio físico do homem, que exercem ou podem exercer efeito deletério sobre seu bem-estar físico, mental e social, portanto, é um fator importante para a fixação, desenvolvimento sócio-econômico e saúde de uma comunidade, em especial as agrícolas. Estudos do INCRA (2010) apontam que apenas 13\% dos assentamentos rurais da reforma agrária no Brasil têm tratamento adequado para o esgotamento sanitário e 79\% tem acesso suficiente à água, sendo que, segundo, o Movimento dos Sem Terra MST (2010) somente 45\% dos assentamentos rurais no Brasil tem acesso a água potável.

Nessa situação, pode-se citar, inclusive, os assentamentos da região do Pontal do Paranapanema, que conforme Fernandes e Ramalho (2001) é a região do estado de São Paulo com maior número de assentamentos e de famílias assentadas, onde se situa 0 município de Teodoro Sampaio.

As condições expostas anteriormente retratam o que seria a falta de um planejamento de instalação de um sistema de saneamento básico, apresentando risco de impacto ás águas subterrâneas, ao solo e consequentemente a saúde da população assentada influenciando diretamente na qualidade de vida.

Portanto, o presente artigo tem como objetivo refletir a cerca da relação entre o saneamento básico e a qualidade de vida nos assentamentos rurais da reforma agrária no município de Teodoro Sampaio - SP.

Os projetos de assentamentos em Teodoro Sampaio tiveram inicio em meados da década de 80, impulsionados pelo processo de ocupação territorial movido por grupos de agricultores, que por conta de uma estrutura agrária latifundiária não tinham acesso a terra, e organizaram-se no Movimento dos Trabalhadores Rurais (MST) para reivindicar a 


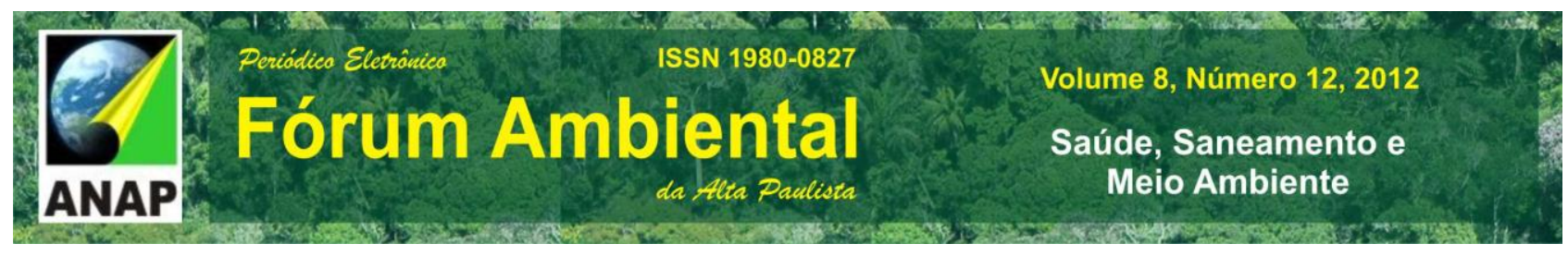

terra e consequentemente a melhoria na qualidade de vida (VALENCIANO; 2001). Devido a este fato a cidade de Teodoro Sampaio atualmente é conhecida como sendo a "capital da Reforma Agrária", e encontra-se inserida nesse processo de forma especial, sendo hoje representante da luta pela terra no Pontal do Paranapanema.

Frente à relevante importância no cenário da reforma agrária apresentada pelos assentamentos rurais na cidade de Teodoro Sampaio, os mesmos são objeto de estudo no presente artigo. A partir de então busca-se refletir a cerca da relação entre o saneamento básico e a qualidade de vida, partindo das metodologias de pesquisa bibliográfica que abrange a bibliografia já tornada publica em relação ao tema de estudo e a pesquisa documental que tem como fonte de coleta de dados documentos constituídos de dados primários que correspondem, por exemplo, a documentos de arquivos privados, fotografias e material cartográfico (LAKATOS; MARCONI, 2003).

Diante deste quadro analítico expositivo, argumenta-se a necessidade de tal reflexão a respeito da influência do saneamento básico na qualidade de vida dos assentados do município de Teodoro Sampaio, sendo que o presente artigo pode ser utilizado como ferramenta para reivindicação de melhoria nas condições de infraestrutura e saneamento básico.

\section{O SANEAMENTO BÁSICO}

O termo saneamento básico define um conjunto de procedimentos adotados por um governo com o objetivo de proporcionar uma situação higiênica e saudável para sua população urbana e rural. Com estas medidas é possível garantir a qualidade de vida e a promoção da saúde, evitando assim a proliferação de doenças. Ao mesmo tempo, garante-se a preservação do meio ambiente e facilita-se a atividade econômica. BRASIL (2004, p. 12) traz o conceito de saneamento, dizendo que este é:

O conjunto de ações socioeconômicas que têm por objetivo alcançar Salubridade Ambiental, por meio de abastecimento de água potável, coleta e disposição sanitária de resíduos sólidos, líquidos e gasosos, promoção da disciplina sanitária de uso do solo, drenagem urbana, controle de doenças transmissíveis e demais serviços e obras 
especializadas, com a finalidade de proteger e melhorar as condições de vida urbana e rural.

O saneamento básico no Brasil é compreendido por quatro serviços: o abastecimento de água potável, o esgotamento sanitário, a gestão de resíduos sólidos e o manejo de águas pluviais (SANTONI, 2010).

A água potável é a água própria para consumo humano, que para assim ser considerada, deve atender aos padrões estabelecidos pela legislação vigente do ministério da saúde. Para assegurar esta potabilidade, deve-se implantar um sistema de abastecimento de água, o qual além da infraestrutura de distribuição oferece tratamento para assegurar a retirada de substâncias indesejáveis e a inativação de microorganismos através da adição de produtos químicos como o cloro (BARROS et. al, 1995).

O esgotamento sanitário é uma forma adequada do ponto de vista sanitário e ambiental de tratamento do esgoto doméstico que compreende a coleta, transporte, tratamento e disposição final. O sistema de esgotos existe para afastar a possibilidade de contato de dejetos humanos com a população, com as águas de abastecimento, com vetores de doenças e alimentos (RIBEIRO; ROOKE, 2010). Em propriedades rurais a melhor maneira de se tratar o esgoto é a utilização de fossa séptica, que são unidades simples de tratamento fundamentais no combate de doenças, verminoses, pois evitam o lançamento dos dejetos humanos diretamente em rios, lagos, solo e águas subterrâneas. Segundo o INCRA (2010) 87\% dos assentamentos da reforma agrária no Brasil não tem sistemas de fossa séptica.

O gerenciamento dos resíduos sólidos é de grande importância dentro das medidas de saneamento, tal gestão compreende a destinação correta do lixo, que é constituído de substâncias putrescíveis, combustíveis e incombustíveis. Quando ele é disposto de forma inadequada, em lixões ao a céu aberto, os problemas ambientais e sanitários são inevitáveis (APETRES, 2009).

Segundo Darolt (2002) o lixo rural é composto por materiais associados à produção agrícola: restos vegetais da cultura, materiais orgânicos, adubos químicos, defensivos e suas embalagens, dejetos animais, produtos veterinários. E por sobras semelhantes às produzidas nas cidades: restos de alimentos, vidros, latas, papéis, papelões, plásticos, pilhas e baterias, lâmpadas, etc. 


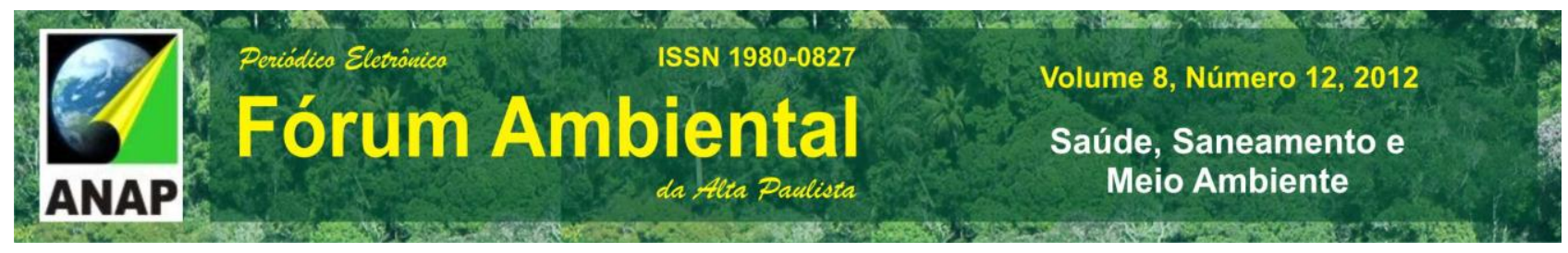

Oliveira e Santos (2009) destacam que na maioria das comunidades rurais Brasileiras não há serviço de coleta de lixo, o que acarreta, caso sua exposição seja feita de forma incorreta, maior risco de poluição do ambiente e comprometimento da saúde das pessoas.

Apesar de ter o básico no nome, saneamento no Brasil não é uma realidade para todo mundo, segundo a Pesquisa Nacional de Saneamento Básico - PNSB do Instituto Brasileiro de Geografia e Estatística - IBGE (2010) somente 44\% da população brasileira tem acesso a rede de esgotamento sanitário e apenas $29,4 \%$ é tratado, quanto à água tratada somente $78,6 \%$ tem acesso.

Com relação aos resultados da pesquisa, a falta de acesso ao esgotamento sanitário e a água tratada, junto com aos demais componentes do saneamento básico, como a disposição de resíduos sólidos e o manejo de águas pluviais, podem comprometer a saúde, bem-estar e a qualidade de vida da sociedade, contribuindo também com a degradação ambiental. Segundo Santoni (2010) existem diversos estudos que relacionam a ausência de saneamento básico com altos índices de internações hospitalares, proliferação de doenças de veiculação hídrica e elevadas taxas de mortalidade, especialmente a infantil.

De acordo com a Organização das Nações Unidas - ONU (2008), a população mundial ultrapassa a marca impressionante de mais de 6 bilhões de habitantes. Destes, 2,6 bilhões, ou seja, 40\% não têm acesso à rede de coleta de tratamento de esgotos. São 200 milhões de toneladas de dejetos humanos lançados anualmente em nossos rios e lagos. Como conseqüência, a cada 20 segundos uma criança morre em função de doenças de veiculação hídrica (diarréia, cólera, tifo, etc.). Isto significa 1,5 milhões de mortes de crianças a cada ano.

Em relação ao saneamento em assentamentos rurais segundo Barreto e Khan (2006) o acesso a água tratada e a destinação adequada do esgoto doméstico, asseguram aos assentados menores níveis de incidência de doenças, e, portanto, um padrão mais elevado de qualidade de vida.

O saneamento básico contribui decisivamente para a qualidade do ambiente e da saúde. Em locais onde se verifica inexistência ou precariedade do esgotamento sanitário, disposição de resíduos sólidos a céu aberto, há proliferação de insetos e roedores 


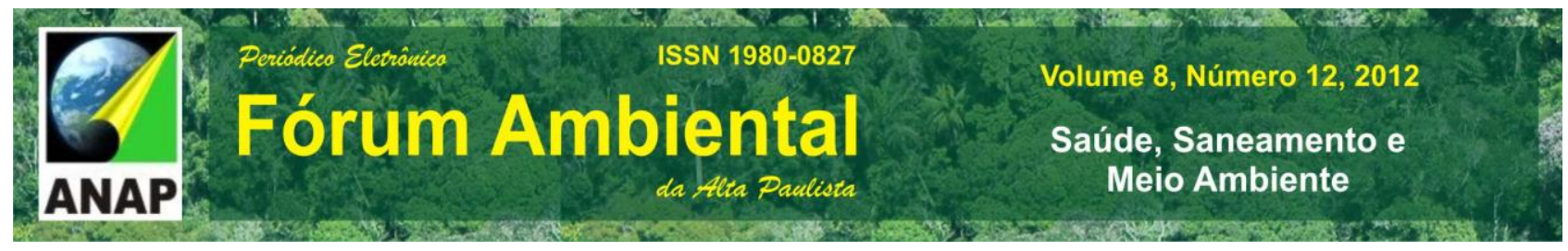

vetores, agentes contaminantes que podem ser disseminados e alcançar as fontes de água e os reservatórios de armazenamento e conseqüentemente gerar doenças infecciosas relacionadas com excretas, lixo e vetores podem atingir a população exposta

Porém, para May et. al. (2008) no meio rural brasileiro o déficit de ações em saneamento básico ainda é elevado. A inexistência de serviços e infraestrutura em saneamento propiciam o desenvolvimento de práticas cotidianas pelos moradores, o que provocam impactos nos recursos naturais. Sendo assim, juntamente com a adequação dos serviços e estrutura em saneamento no meio rural, é de importância maior que as atitudes governamentais e comportamentos da população local sejam mudados para que ocorram gerenciamento e preservação dos recursos naturais locais.

A situação do saneamento Brasileiro é trágica e muito lenta, de acordo com a Pesquisa Nacional por amostra de Domicílios de 2009 - PNAD (2009), de 1995 a 2009 a coleta de esgotos aumentou apenas 11,6 pontos percentuais. De 2003 a 2009 , a coleta aumentou apenas quatro pontos percentuais. A coleta de esgotos chegou a cair de 59,3\% em 2008 para 59,1\% em 2009. Também de acordo com o PNSB (2010) o saneamento é muito heterogêneo, as unidades da federação com mais da metade dos domicílios atendidos em coleta de esgotos são Distrito Federal (86,3\%), São Paulo (82,1\%) e Minas Gerais (68,9\%). As menores coberturas são Amapá (3,5\%), Pará (1,7\%) e Rondônia $(1,6 \%)$.

A situação do saneamento nas zonas rurais brasileiras é ainda mais crítica. Segundo o Programa das Nações Unidas para o Desenvolvimento - PNUD (2010), 76,9\% da população rural não têm acesso a esgotamento sanitário adequado. A situação brasileira é pior do que a de países como o Sudão, o Timor Leste e o Afeganistão.

Neste contexto, fica claro a falta de compromisso do governo com o saneamento básico, e que a sua inexistência pode afetar diretamente a saúde e a qualidade de vida das comunidades.

\section{QUALIDADE DE VIDA E SUA RELAÇÃO COM O SANEAMENTO BÁSICO}

Embora só recentemente a preocupação em relação ao tema qualidade de vida tenha se intensificado, ela já se apresentava bem antes de despertar a necessidade do 


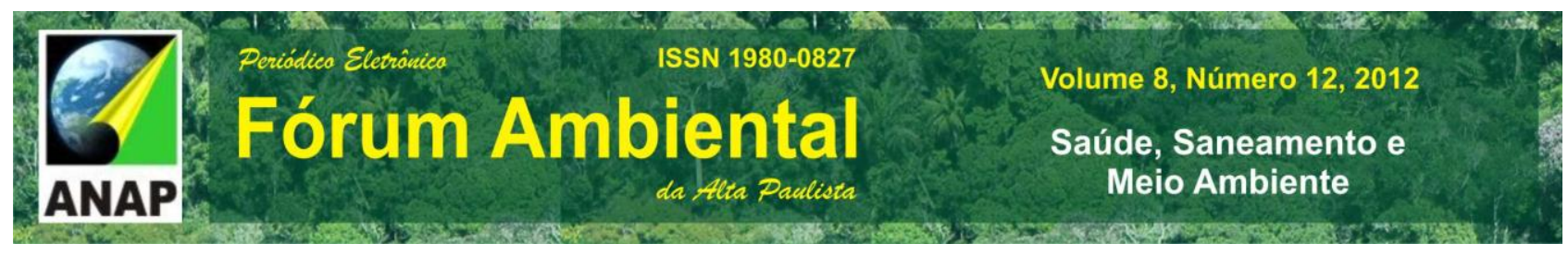

estabelecimento de parâmetros que tornasse possível a sua apreensão e conseqüente aferição.

$\mathrm{Na}$ antiguidade as civilizações buscavam a qualidade de vida na satisfação imediata de suas necessidades, já na idade média com o domínio da filosofia cristã qualidade de vida estava condicionada a seguir fielmente os preceitos dogmáticos da igreja Católica, na modernidade às revoluções econômicas, social, políticas e a evolução do capitalismo limitaram a qualidade de vida na concentração de riquezas e na satisfação de necessidades materiais e culturais (SOUZA, KHAN, PASSOS, 2004).

Almeida e Gutierres (2004), afirmam que a crescente preocupação com questões relacionadas à qualidade de vida vem no sentido de valorizar parâmetros mais amplos do que no controle de sintomas, a diminuição da mortalidade ou aumento da expectativa de vida. A qualidade de vida passou de uma abordagem mais centrada na saúde, para um conceito abrangente em que as condições e estilo de vida constituem aspectos a serem considerados.

O termo qualidade de vida abrange muitos significados, e segundo a OMS pode ser um método utilizado para medir as condições de vida de um ser humano, envolvendo diversos aspectos como: bem-estar social, mental, psicológico e também a saúde e saneamento básico. Mesmo não existindo um conceito universal para qualidade de vida, este tema tem se constituído em preocupação mundial nos últimos anos (SILVA, 2000).

Segundo relatos de Khan e Passos (2002), a Organização das Nações Unidas (ONU), vem utilizando o Índice de Desenvolvimento Humano (IDH), para avaliar as condições de vida nos países membros da organização, atribuindo pontuações de zero a 1 de acordo com seu grau de desenvolvimento em três áreas: renda, educação e expectativa de vida. Ainda de acordo com os autores tais indicadores promovem a possibilidade de se averiguar se as pessoas estão aptas a desfrutar dos benefícios mais subjetivos e imensuráveis do desenvolvimento, como acesso a informação e participação política.

Segundo Instituto Trata Brasil (2010), o saneamento básico é uma das condições necessárias para a qualidade de vida de uma população e sua ausência compromete a saúde e bem estar das pessoas. Qualquer que seja a definição a respeito da qualidade de vida deve-se considerar a promoção do bem-estar do ser humano que está intimamente 


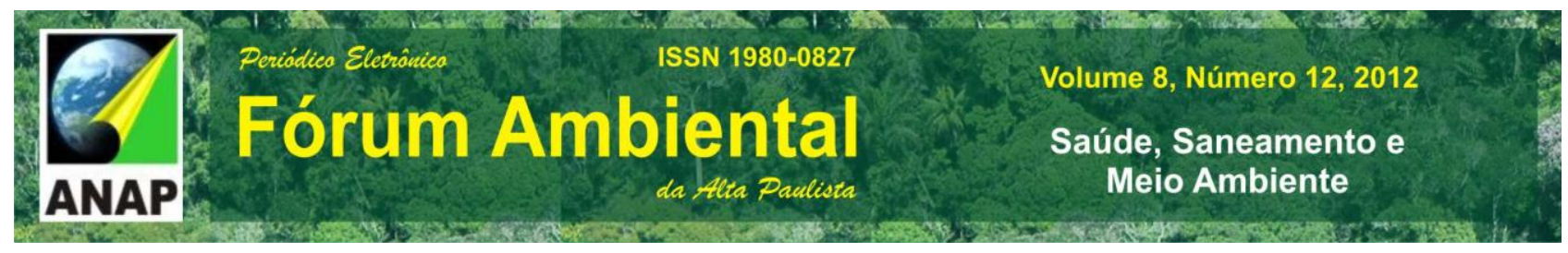

relacionado com o saneamento básico, pois a inexistência do mesmo afeta a saúde do ser humano, segundo dados da OMS (2008) a falta de saneamento básico é uma das principais causas da mortalidade infantil no Brasil causada por doenças parasitárias (dengue, malária, cólera, febre amarela, teníase, cisticercose, esquistossomose, diarréia, etc.) e doenças infecciosas (hepatite $A$, amebíase, dentre outras), também outro aspecto negativo da falta de saneamento básico é com relação a educação, Neste setor, pesquisas da Fundação Getúlio Vargas - FGV (2008) mostraram que o grande impacto negativo está no aproveitamento das crianças. Por viverem e estudarem em ambientes sem condição sanitária adequada, as crianças têm aproveitamento $18 \%$ menor e apresentam índices de reprovação 46\% maior interferindo na sua qualidade de vida.

Todo este contexto enfatiza que a promoção da qualidade de vida do individuo se encontra intrinsecamente relacionada com a qualidade do saneamento e dos recursos naturais, não só nas cidades, mas também nas áreas rurais, principalmente nos assentamentos da reforma agrária Brasileira, aqui neste artigo representados pela região do Pontal do Paranapanema especificamente a cidade de Teodoro Sampaio considerada a "capital da Reforma Agrária", onde há uma grande concentração de famílias assentadas que também tem direito ao saneamento e a uma boa qualidade de vida.

\section{ASPECTOS GERAIS DO PONTAL DO PARANAPANEMA}

O Pontal do Paranapanema localiza-se no extremo Oeste do Estado de São Paulo. Segundo Franzini (2010) a região ocupa uma área com $11.838 \mathrm{Km}^{2}$ e é formada por um conjunto de 32 municípios total ou parcialmente inseridos, com uma população aproximada de 534 mil habitantes.

De forma geral, a ocupação na região do Pontal caracteriza-se pela instalação de assentamentos rurais, com pequenas propriedades agrupadas em glebas e ocupadas por famílias, cujas principais atividades econômicas desenvolvidas são a pecuária e a agricultura, e o atendimento das necessidades de saneamento básico como acesso a água para consumo, destinação de resíduos e esgotamento sanitário destas propriedades é muitas vezes precária, afetando diretamente na saúde e consequentemente a qualidade de vida da comunidade assentada. 


\subsection{A Ocupação territorial no Pontal do Paranapanema}

De acordo com Rodrigues e Galvão (2006) até a década de 50 a região oeste do Pontal do Paranapanema, com aproximadamente 247.000 ha, era conhecida pela exuberância de sua fauna e flora, a ponto de, por meio de decreto ser transformada em reserva, recebendo a denominação de "Grande Reserva do Pontal".

No entanto, a partir dos anos 50, deu-se início a uma ocupação desordenada, caracterizada pela grilagem de terras, em sua maioria, julgadas como devolutas, e sucessão de desmandos por latifundiário, que chegaram a concentrar $75 \%$ dos 247.000 hectares da Grande Reserva do Pontal.

$\mathrm{Na}$ década de 90 ocorre a chegada do MST na região do pontal que promove ocupações de áreas dos grandes latifúndios gerando uma redistribuição dessas terras por meio da reforma agrária. Como resultado, em 1995, a região do Pontal do Paranapanema era uma das principais áreas de conflitos fundiários do país, tendo o maior número de ocupações de terra (RAMALHOS, 2002), sendo que, no ano de 2007, conforme dados obtido no Sistema de Informações Territoriais (SIT), a região contava com um total de 5.853 famílias assentadas.

\subsection{O Município de Teodoro Sampaio}

De acordo com dados do Censo de 2010 obtidos pelo Instituto Brasileiro de Geografia e Estatística (IBGE) o município de Teodoro Sampaio conta com 21.389 habitantes, sendo 17.386 pertencentes a área urbana e 4.021 a área rural.

Segundo o INCRA em 2007 Teodoro Sampaio contava com 853 famílias assentadas em 20 assentamentos, distribuídos em diferentes áreas de ocupação, sendo aqueles mais próximos à áreas de preservação permanente, como o assentamento ribeirão bonito e aqueles próximos à destilaria e plantações de cana de açúcar. Essas características são de extrema importância, pois influenciam, no manejo da terra e os 


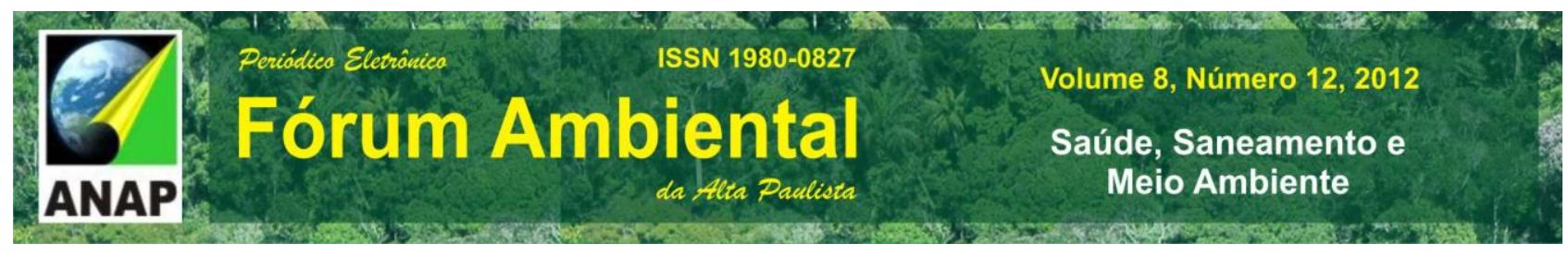

tipos de atividades agropecuárias, assim podendo interferir na qualidade das águas subterrâneas e consequentemente na saúde dos assentados.

De forma geral, segundo Valenciano (2001, p 23) "a implantação desses assentamentos incentivou uma significativa alteração das condições locais de produção, com elevado impacto econômico, político e social, não só local, mas também regional".

No entanto, apesar da importância destes assentamentos para a região, quando se analisa a questão ambiental, infraestrutura, qualidade de vida entre outros fatores, comumente necessários para favorecer a fixação do trabalhador no campo, percebe-se que a situação ainda é precária em alguns assentamentos, e esforços tanto do governo quanto de Organizações não Governamentais (ONG's) é de extrema importância.

Em Teodoro Sampaio, essa situação pode ser percebida quando se analisa o Plano de Desenvolvimento Rural Sustentável do Município para os anos de 2010 - 2013, na zona rural do município não há coleta de lixo nem coleta de esgotos, cerca de $99 \%$ dos líquidos são laçados em fossa negra e a grande maioria do lixo doméstico é queimado ou enterrado e a água para consumo humano é proveniente de poços sem tratamento previsto nas legislações.

Como pode ser observado o acesso ao saneamento básico é praticamente inexistente, tal situação além de diminuir a qualidade de vida pode levar também à deterioração dos recursos ambientais dificultando ainda mais a permanência do agricultor na terra.

A falta de infraestrutura adequada nos assentamentos rurais em Teodoro Sampaio reflete o que acontece na maioria dos assentamentos no Brasil. Tal problema influi na qualidade de vida dos assentados em vários aspectos, desde a falta de recursos para o manejo da terra que leva a comunidade muitas vezes abandonar o lote e trabalhar na indústria sucroalcooleira para sustento da família, até a falta de saneamento que afeta a saúde, diminuindo assim a qualidade de vida tão reivindicada no movimento da reforma agrária.

Existem entidades não governamentais que atuam nos assentamentos em todo território Brasileiro trabalhando para a restauração e manutenção do meio ambiente e na melhoria da qualidade de vida, pode-se citar o exemplo do Instituto de Pesquisas Tecnológicas (IPE) que atua na região de Teodoro Sampaio, mesmo sendo uma 
organização que tem na conservação da natureza o sentido da sua ação, tem o compromisso de contribuir na melhoria da qualidade de vida dos seus parceiros assentados (IPE, 2000).

Mas somente a ajuda destas instituições não é suficiente tendo em vista que é de responsabilidade do governo 0 fornecimento de infraestrutura nos assentamentos garantindo o acesso ao saneamento básico, contribuindo assim com a manutenção da saúde e consequentemente melhorando a qualidade de vida da comunidade assentada.

\section{CONSIDERAÇÕES FINAIS}

Existem diversos significados para qualidade de vida, mas é inegável que não se tem qualidade de vida sem saúde, e para uma boa manutenção da saúde de uma comunidade é importante o acesso a condições mínimas de saneamento. O saneamento básico é fator na proteção à qualidade de vida e a falta deste hoje é um problema grave enfrentado pelo Brasil.

A Constituição da Organização Mundial da Saúde (OMS) estabelece que o gozo do melhor estado de saúde é um direito fundamental de todos os seres humanos, sejam quais forem suas raças, religiões, opiniões políticas, condições econômicas e sociais, e que saúde é o estado de completo bem estar físico, mental e social e não apenas a ausência de doenças.

Segundo o IBGE (2010) quase metade dos municípios do país ainda não estão ligados a uma rede coletora de esgotos. No meio rural o cenário é ainda mais critico 0 descarte do esgoto, na maioria das vezes é feito de forma incorreta ou a céu aberto aumentando o risco de doenças.

Porém, de acordo com a Fundação Nacional de Saúde - FUNASA (2012) atualmente existe o Programa Nacional de Saneamento Rural, para dar inicio a regularização dos sistemas de saneamento principalmente nos assentamentos rurais da reforma agrária, que tem uma grande concentração de famílias com sua qualidade de vida prejudicada pela falta de saneamento, mas o processo ainda é muito lento e burocrático. 


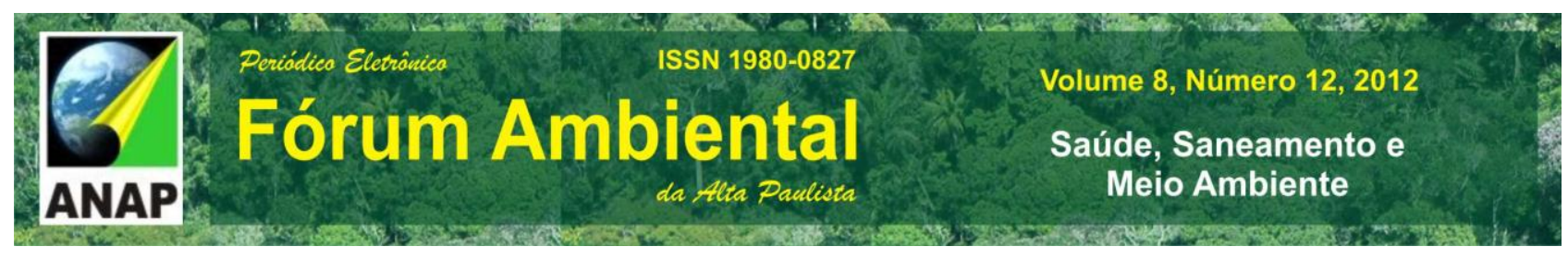

A cidade de Teodoro Sampaio conhecida como a "capital da reforma agrária", deveria ter seus assentamentos como verdadeiro exemplo da reforma agrária, que objetiva o alcance de uma igualdade social maior, de melhor distribuição do poder político, de melhorias de ordem econômica e principalmente oferecer uma boa qualidade de vida as famílias assentadas. Mas como mostra o Plano Municipal de Desenvolvimento Rural Sustentável (2010), os assentamentos da cidade estão longe de ser exemplo principalmente no quesito saneamento básico. Sabe-se, porém que, para servir de bom exemplo é necessário vencer as dificuldades do projeto da reforma agrária que é complexo e envolve um grande número de agentes, portanto cabe a todos os envolvidos, desenvolver um planejamento condizente com a realidade e particularidade de cada assentamento.

É inegável a importância dos serviços de saneamento básico, para assegurar a qualidade de vida, e como objeto de reflexão os assentamentos rurais de Teodoro Sampaio mostram o que acontece na maioria dos assentamentos brasileiros com a falta de infraestrutura e saneamento básico. Isto reforça a ideia de que somente o acesso a terra não garante qualidade de vida.

\section{REFERÊNCIAS}

ALMEIDA, M.; GUITIERREZ, G. Políticas Públicas de Lazer e qualidade de vida: A Contribuição do Conceito de Cultura para Pensar as Políticas de Lazer. (67-84). In: Vilarta, Roberto. Qualidade de Vida e Políticas Públicas: Saúde, Lazer e Atividade Física. Campinas, Sp: Ipes Editorial, 2004.

BARROS, R. T. V. et al. Saneamento. Belo Horizonte: Escola de Engenharia da UFMG, 1995. (Manual de saneamento e proteção ambiental para os municípios - volume 2)

BARRETO, R. S. C; KHAN, A. S. Capital Social e Qualidade de Vida dos Assentamentos do Município de Caucaia - CE 45 Congresso Sociedade Brasileira de Economia e Sociologia Rural 23 a 27 de Julho de 2006 - Fortaleza - Brasil.

BRASIL. FUNDAÇÃO NACIONAL DE SAÚDE (FUNASA). Manual de saneamento. 3. ed. ver. Brasília: Fundação Nacional de Saúde, 2004.

DAROLT, M. R. Agricultura Orgânica: inventando o futuro. Londrina: IAPAR, 2002.

FERNANDES, B. M.; RAMALHO, C.B. Luta pela terra e desenvolvimento rural no Pontal do Paranapanema (SP), Estudos Avançados, v.15, n.43, 2001. Disponível em: http://www.scielo.br/pdf/ea/v15n43/v15n43a18.pdf, Acesso em 02/06/2012. 


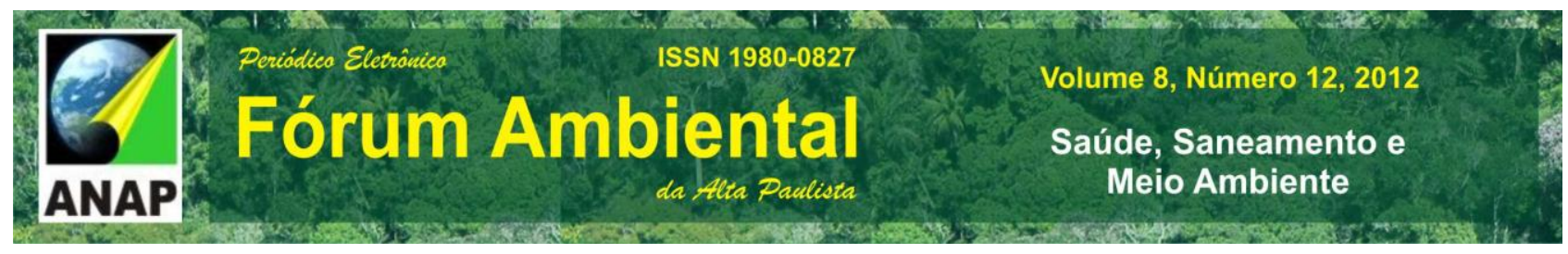

FILHO, J. D; SANTOS, D. C. G. Avaliação das Condições de Saneamento num Assentamento em Sergipe. In $21^{\circ}$ Congresso Brasileiro de Engenharia Sanitária e Ambiental 16 a 21 de setembro de 2001 - João Pessoa - PB - Brasil. Disponível em: http://www.bvsde.paho.org/bvsaidis/brasil21/vii-002.pdf. Acesso em: 01 junho de 2012,

FRANZINI, A. S. Avaliação hidrogeológica em área de assentamento. 2010. 97 f. Dissertação (Mestrado em Geociências e Meio Ambiente) - Instituto de Geociências e Ciências Exatas, Universidade Estadual Paulista, Rio Claro.

INCRA - INSTUTO NACIONAL DE COLONIZAÇÃO E REFORMA AGRÁRIA. Pesquisa sobre a qualidade de vida, Produção e Renda dos Assentamentos da Reforma Agrária - PQRA 2010. Brasília: INCRA, 2010. Disponível em: <www.incra.gov.br>. Acesso 8 de junho de 2012.

INSTITUTO BRASILEIRO DE GEOGRAFIA E ESTATÍSTICA - IBGE. Pesquisa nacional de saneamento básico- PNSB: 2008. Rio de Janeiro: IBGE, 2010.

INSTITUTO BRASILEIRO DE GEOGRAFIA E ESTATÍSTICA - IBGE. Pesquisa nacional por amostras em domicilio PNAD: 2008. Rio de Janeiro: IBGE, 2009.

INSTITUTO TRATA BRASIL. Esgotamento Sanitário Inadequado e seus Impactos na saúde da População. Nov. 2010. Disponível em http://www.tratabrasil.org.br. Acessado em 06 de maio de 2012.

IPE - INSTITUTO DE PESQUISAS ECOLÓGICAS. Sistematização e Análise de Atividades de Extensão Agroflorestal Voltadas ao Desenvolvimento Sustentável de Assentamentos Rurais na Região do Pontal do Paranapanema SP. Informe Técnico, 2000.

KHAN, A. S., PASSOS, A. T. B. Reforma agrária solidária, assistência técnica e desenvolvimento rural no Estado do Ceará. Revista Econômica do Nordeste, Fortaleza, v. 33, n. 3, jul-set. 2002. p.593-614. Disponível

em: http://www.bnb.gov.br/projwebren/Exec/artigoRenPDF.aspx?cd_artigo_ren=293. Acessado em: 10 de maio de 2012.

LAKATOS, E. M; MARCONI, M. A. Fundamentos de Metodologia Científica. $5^{\text {a }}$ Ed. São Paulo: Atlas, 2003.

MAY, M.S.S. et al . Saneamento ambiental em assentamento de trabalhadores rurais: o exemplo de Dandara dos Palmares no município de Camamu-BA.. Online. Disponível em: http://www.semasa.sp.gov.br/Documentos/ASS EMAE/Trab_124.pdf.2008. Acessado em 06 de maio de 2012

MAZZINI, E.J.T. et. al. Assentamentos rurais no Pontal do Paranapanema - SP: uma política de desenvolvimento regional, Revista Formação, n. 14, v. 1, p. 56-66, 2007.

MOVIMENTO DOS TRABALHADORES RURAIS SEM TERRA (MST) apresenta: Os assentamentos publicado em nov. de 2010. Disponível em: http://www.mst.org.br/node/8606 Acesso em: 06 maio 2012. 


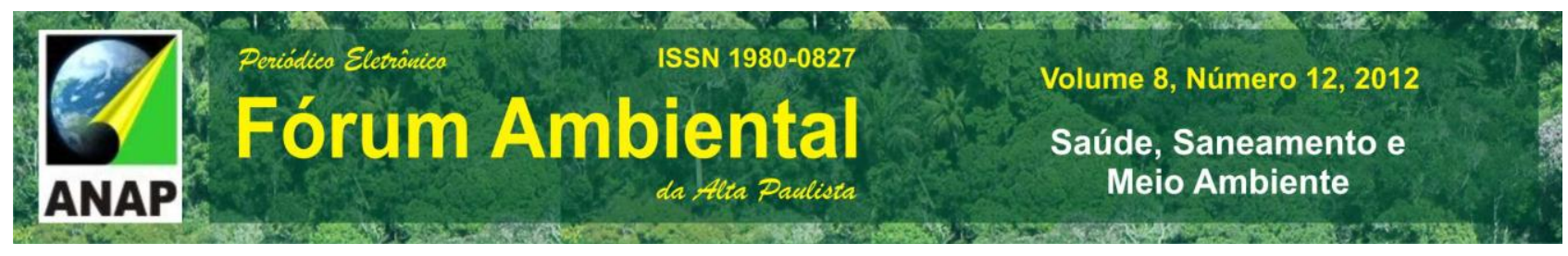

OLIVEIRA, F. G.; SANTOS, E. G. Resíduos sólidos no meio rural: o caso do Assentamento queimadas no município de Remígio/PB. In. I CONGRESSO PARAIBANO DE GESTÃO DO LIXO: Educação Ambiental e sustentabilidade". 23 a 25 de setembro de 2009. Campina

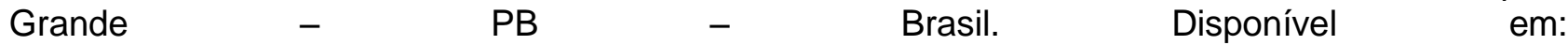
http://universidadescidadas.ufcg.edu.br/uploads/documentos/publicacoes/ResiduosSolidosNoMeio Rural_ICongressoParaibanoLixo.pdf. Acesso em : 2 de julho de 2012.

RIBEIRO, J. W. ; ROOKE, J. M. S . Saneamento Básico e a Sua Relação com o Meio Ambiente e a Saúde Publica. 2010. 28 f. Trabalho de conclusão de curso ( Especialização em Análise Ambiental) - Universidade Federal de Juiz de Fora, Juiz de Fora.

RODRIGUES, E. R.; GALVÃO, F. Florística e fitossociologia de uma área de reserva legal recuperada por meio de sistema agroflorestal na região do Pontal do Paranapanema. Floresta, Curitiba, PR, v. 36, n. 2, mai./ago. 2006.

RAMALHOS, C.B. Impactos socioterritoriais dos assentamentos rurais no Município do mirante do Paranapanema/ Região do Pontal do Paranapanema. SP. 2002. 144f. Dissertação (Mestrado) Universidade Estadual Paulista.

SANTONI, L. Saneamento Básico e Desigualdades: o financiamento federal da política pública (2003 - 2009). 2010. 161 f. Dissertação Mestrado (Centro de Desenvolvimento Sustentável) Universidade de Brasília, Brasília

SOUZA, M. C; KHAN, A. S; PASSOS, A. T. B. Qualidade de Vida da Agricultura Familiar em Assentamentos de Reforma Agrária no Rio Grande do Norte. In. XLII CONGRESSO DA SOBER. 25 a 28 de Julho de 2004 - Cuiabá-MT - Brasil. Disponível em: http://www.sober.org.br/palestra/12/110484. Acesso em: 01 junho de 2012.

SILVA, A. K. M. Perfil sócio-econômico e nível de qualidade de vida dos produtores rurais do município de Mossoró-RN. 55 fs. Monografia, (Graduação em Engenharia Agronômica), Escola Superior de Agricultura de Mossoró-ESAM, Mossoró, 2000.

TEODORO SAMPAIO. (Município). Plano Municipal de Desenvolvimento Rural Sustentável (2010 - 2013). Teodoro Sampaio, 18 de junho de 2010.

VALENCIANO, R.C. Processo de luta pela terra e seus desdodabrementos no município de Teodoro Sampaio, Revista Pegada v. 2, n. 1, 2001. Disponível em: http://revista.fct.unesp.br/index.php/pegada/article/view/778 Acesso 06 maio 2012. 